\title{
STUDY OF PEDESTRIAN COMFORT IN A THREE SPAN STRESS RIBBON FOOTBRIDGE WITH CARBON FIBRE CABLES
}

\author{
LUIS ROMERA, SANTIAGO HERNÁNDEZ, AITOR BALDOMIR \& FELIX NIETO \\ School of Civil Engineering, University of La Coruna, Spain
}

\begin{abstract}
Many footbridges have been built in the recent past and there is a trend to design them as very flexible structures. This increased flexibility has had some undesired effects as unexpected vibrations under pedestrian loads, mainly in lateral direction, had occurred in several footbridges in different countries; amongst them those happening on the Millennium Bridge in London attracted a lot of publicity. As a consequence the behavior of people walking along this construction and the dynamic load produced is already known more precisely and it is better understood now. A conclusion extracted is that not only vertical forces but also lateral component of pedestrian load need to be taken into account in the analysis. In this paper a study carried out to an innovative three span stress ribbon footbridge is presented. First, the structure is described narrating summarily the construction steps to make clear the need to consider nonlinear analysis to identify the footbridge geometry at the end of the construction, which is the baseline to obtain the eigenfrequencies. The objective of the work in this paper was to evaluate the lateral vibrations of the structure under pedestrian loads and for doing that several scenarios of people walking along one span or the full length of the footbridge and different definitions of the dynamic loads including vertical and lateral force components were considered.

Keywords: footbridges, stress ribbon structures, nonlinear analysis, pedestrian loads, modal analysis, footbridges vibrations, pedestrian comfort.
\end{abstract}

\section{INTRODUCTION}

Footbridges are constantly built in many places to provide crossings in urban places, parks or natural surroundings. They are usually designed as very flexible structures in a trend to create innovative typological solutions. Due to these circumstances several footbridges have experienced problems in the past due to excessive vibrations produced by pedestrians walking along the structure. In the case of the Toda Park Bridge in Japan high lateral vibrations were observed after its opening [1]. Other structures as the Auckland Harbour Road Bridge in New Zealand [2], the Solferino Bridge in Paris [3] or the Alexandra Bridge in Canada [4] moved laterally when a crowd of pedestrians was standing on the bridge.

More recently, the problems arisen in the London Millennium Bridge were very much publicized. The closure of that crossing soon after its opening and the studies carried out to identify a solution to the excessive horizontal displacement occurred the first day produced several publications [5]-[7]. As a consequence some other constructions, mainly suspension bridges, have been investigated to find out its serviceability [8]-[10].

Both, practical cases and research papers, have proved that slender footbridges are prone to lateral vibrations and this kind of displacement is more uncomfortable to pedestrians than the vertical deflection. People feel unsafe with small horizontal movements and in a defensive behavior, they tend to accommodate their walking pace to bridge displacement, that increases by this coupling. This circumstance worsens until the pedestrians stop walking when they feel worried enough and the situation is reversed. Nevertheless, the main objective in a footbridge design is to produce a construction that is serviceable and therefore it is of crucial importance to know the dynamic response to find out if the vibrations produced by pedestrians will be below a convenient threshold. In that regards the definition of loads 
produced by pedestrians and the limits posed for the vibrations are of great relevance and consequently extensive surveys of dynamic behavior of footbridges can be found [11].

\section{MODELS FOR PEDESTRIAN LOADS}

Pedestrians walking on footbridge produce vertical, longitudinal and lateral forces. Only the vertical component was considered in early times. Lateral component was included in the studies only recently as it was considered the source of the relevant vibrations in this class of flexible structures. Longitudinal force continues to be excluded as the stiffness of the footbridges in that direction is high enough and no contribution to misbehaviours in real constructions has been reported. Usually pedestrian forces are modelled as periodic loads represented by Fourier series as described in the ISO 10137 code [12]. In the case of the vertical force of a pedestrian the equation is

$$
f_{v}(t)=P\left(1+\sum_{n=1}^{k} a_{v n} \sin \left(2 \pi n f t+\phi_{v n}\right)\right),
$$

where $P$ is the pedestrian weight, $a_{v n}$ is the load coefficient of the $n$-th harmonic, $f$ is the force frequency, $\phi_{v n}$ is the phase angle of the $n$-th harmonic and $K$ is the number of harmonics considered.

An early publication by Blanchard et al. [13] only included two terms in eqn (1). Bachmann and Ammann [14] enlarged up to five the number of harmonics. More recently Young [15] presented the work of several researchers. In the models of Blanchard, Bauchmann and Ammann coefficients $a_{v n}$ are constants. The most relevant $a_{v l}$ ranges around of 0.257 in the former and 0.37 in the latter. On the other hand, Young makes $a_{v n}$ linear function of the force frequency.

Regarding to the lateral force several approaches have been presented. A model by Dallard et al. [16] defines that force as a linear function of the lateral velocity of the bridge. This concept is simple but can lead to ever increasing displacements that are not in agreement with the real phenomenon. A research by Nakamura [17] based on findings from the vibrations of the Toda Bridge, in Japan, takes into account the synchronization of pedestrians to the footbridge movements and eliminates the monotonically increasing values of Dallard's model. In the case of ISO 10137 code the lateral force is defined similarly as the vertical component

$$
f_{h}(t)=P\left(1+\sum_{n=1}^{k} a_{h n} \sin \left(2 \pi n f t+\phi_{h n}\right)\right),
$$

where again $P$ is the pedestrian weight, $a_{h n}$ and $\phi_{h n}$ are the coefficients and phase angle of the $n$-th harmonic and $f$ is the load frequency.

Regarding to the frequency of the pedestrian load is commonly accepted that an average walking pace corresponds to a frequency of $2 \mathrm{~Hz}$ and an interval between $1.4 \mathrm{~Hz}$ and $2.4 \mathrm{~Hz}$ can be considered for slow to fast walking. Therefore, footbridges having vertical frequencies in this range of values could be prone to experience significant vibrations. Lateral pedestrian force comes at half frequency, thus in the interval of $0.7-1.2 \mathrm{~Hz}$ and therefore the lateral eigenmodes with values inside or close to that values are of interest.

Identification of pedestrian loads in a footbridge requires finding out the forces produced not by a single pedestrian but for a group or a crowd crossing the bridge. It has been observed that when structural vibrations occur pedestrians start to synchronize to some degree and this behaviour can lead initially to increase bridge displacements but as soon as people start 
feeling unsafe they stop walking so the dynamic forces diminish. ISO 10137 indicates that the total dynamic force $F_{N}(t)$ produced by a number $N$ of pedestrians can be obtained from the force $f(t)$ of a single pedestrian by the equation

$$
F_{N}(t)=f(t) \cdot c(N)
$$

being

$$
c(N)=\sqrt{N} .
$$

Another important issue is the allowable values for the accelerations produced by the dynamic loads. So far only recommended values of the upper limit appears in publications [18] or codes of practice [19].

- Maximum acceleration for vertical vibrations: $0.5-1.0 \mathrm{~m} / \mathrm{s}^{2}$.

- Maximum acceleration for horizontal vibration (normal use): $0.2-0.4 \mathrm{~m} / \mathrm{s}^{2}$.

- Maximum acceleration for horizontal vibration (crowd conditions): $0.4 \mathrm{~m} / \mathrm{s}^{2}$.

\section{THE THREE SPAN STRESS RIBBON FOOTBRIDGE IN CUENCA, SPAIN}

This structure crosses over Júcar river in the city of Cuenca in the nearby of the university area and it is intended to improve the access to the campus. The stress ribbon typology has become very common for footbridges because this innovative solution, made popular by the Czech engineer Jiry Strasky [20], produces very flexible and elegant structures. The Cuenca footbridge has three spans of $72 \mathrm{~m}$ each one, which is a quite significant length for this type of bridges. Deck is composed of carbon fiber cables and prefabricated concrete segments (Figs 1 and 2). The depth of the deck is just $0.34 \mathrm{~m}$ that corresponds to a slenderness of $1 / 211$. The mentioned carbon fiber cables substitute in the bridge the usual steel cables and to the authors knowledge is the first time that this class of material has been used for that purpose in a footbridge.

CFRP cables are been chosen instead of steel strands due the higher tensile strength (from 2000 to $4500 \mathrm{MPa}$ ), higher Young modulus (200-650 GPa), lower density $\left(1.6 \mathrm{~g} / \mathrm{cm}^{3}\right)$, and good fatigue and chemical resistance. Construction of this structure starts by erecting the abutment and intermediate supports, then the cables are prestressed and the prefabricated segments of deck are put in place allowing some space between them that will be filled with concrete afterwards. Then a temporary load is located along the three spans. The next phase consists on pouring concrete in the joints between the prefabricated segments of the deck. Finally, when the concrete has enough strength the temporary load is removed. The geometry of the structure and forces in cables change at each construction step and the structural model of the structure must take in account that circumstance. In this case, a finite element model using the SAP 2000 code [21] was used having 1,840 frame elements and 1,851 nodes and

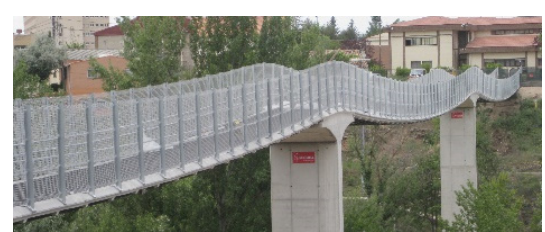

(a)

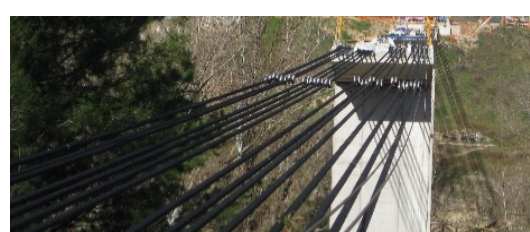

(b)

Figure 1: Views of the stress ribbon footbridge. (a) Overall view; and (b) Detail of carbon fiber cables. 


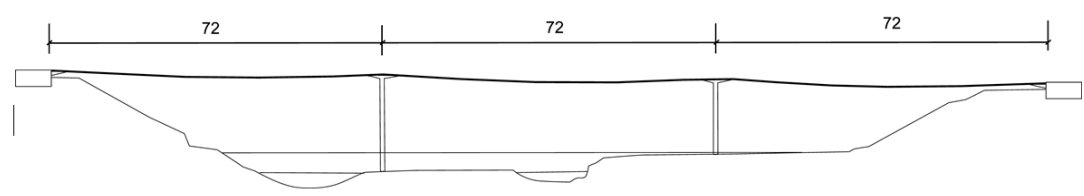

(a)

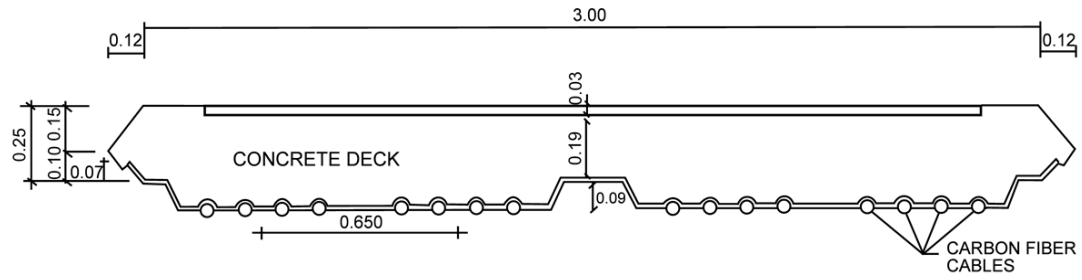

(b)

Figure 2: Geometry of the stress ribbon footbridge. (a) Longitudinal view (dimensions in meters); and (b) Deck cross section (dimensions in meters).

Table 1: First 16 natural frequencies of vibration.

\begin{tabular}{|c|c|c|}
\hline Mode & Frequency $(\mathrm{Hz})$ & Type \\
\hline 1 & 0.567 & Vertical \\
\hline 2 & 0.5737 & Vertical \\
\hline 3 & 1.2218 & Vertical \\
\hline 4 & 1.2359 & Vertical \\
\hline 5 & 1.2428 & Vertical \\
\hline 6 & 1.2696 & Vertical \\
\hline 7 & 1.3005 & Lateral \\
\hline 8 & 1.5418 & Lateral \\
\hline
\end{tabular}

\begin{tabular}{|c|c|c|}
\hline Mode & Frequency $(\mathrm{Hz})$ & Type \\
\hline 9 & 1.8182 & Lateral \\
\hline 10 & 1.9695 & Vertical \\
\hline 11 & 1.9964 & Vertical \\
\hline 12 & 2.0719 & Vertical \\
\hline 13 & 2.1705 & Torsional \\
\hline 14 & 2.3548 & Torsional \\
\hline 15 & 2.5565 & Torsional \\
\hline 16 & 2.8348 & Torsional \\
\hline
\end{tabular}

geometric nonlinearity was considered in the analysis. Natural frequencies were calculated with the geometry of the footbridge after construction and the numerical results appear in Table 1.

The geometry of the vibration modes appears in Fig. 3 for vertical modes, Fig. 4 for lateral modes and Fig. 5 for torsional modes, no coupled lateral-torsional modes have been identified. The special behaviour of the multiple span stress ribbon structure creates several families of geometries of the natural modes. In this case the vertical vibration is represented for four families of natural modes.

Vertical vibration type A corresponds to natural modes in which the central span defines the geometry of the vibration. Vertical vibration type B corresponds to natural modes in which the lateral spans define the geometry of the vibration. Vertical vibration type $\mathrm{C}$ corresponds to natural modes in which each span vibrates independently with symmetric geometry, and vertical vibration type D corresponds to natural modes in which each span vibrates independently with anti-symmetric geometry. Lateral vibration type E: Corresponds to the lateral vibration modes. Torsional vibration type F: Corresponds to the torsional vibration modes. In the figures representing these modes fake transversal bars are presented to make easier the visualization of the deformed geometry. 


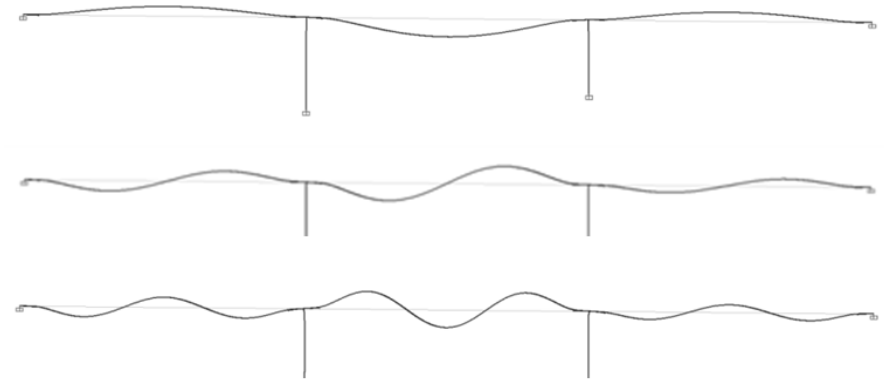

(a)

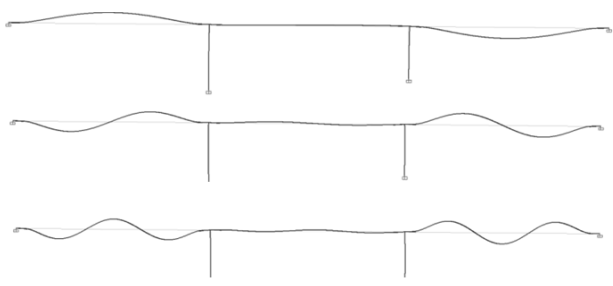

(b)

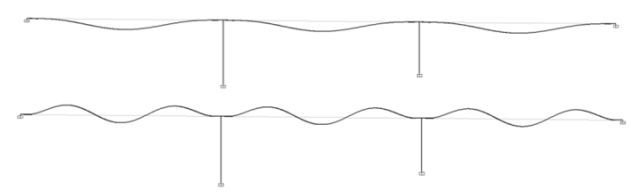

(c)

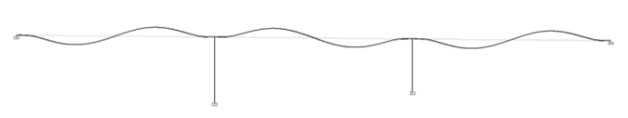

(d)
Mode 1: $0.5671 \mathrm{~Hz}$.

Mode 3: $1.2218 \mathrm{~Hz}$.

Mode 10: $1.9695 \mathrm{~Hz}$
Mode 6: $1.2696 \mathrm{~Hz}$.

Mode 12: 2.0719 Hz.

Figure 3: Geometry of vertical vibration modes. (a) Vertical vibration type A; (b) Vertical vibration type B; (c) Vertical vibration type C; and (d) Vertical vibration type D.

Mode 7: $1.3005 \mathrm{~Hz}$.

Mode 8: $1.5418 \mathrm{~Hz}$.

Mode 9: $1.8182 \mathrm{~Hz}$.

Figure 4: Geometry of lateral vibration modes. 


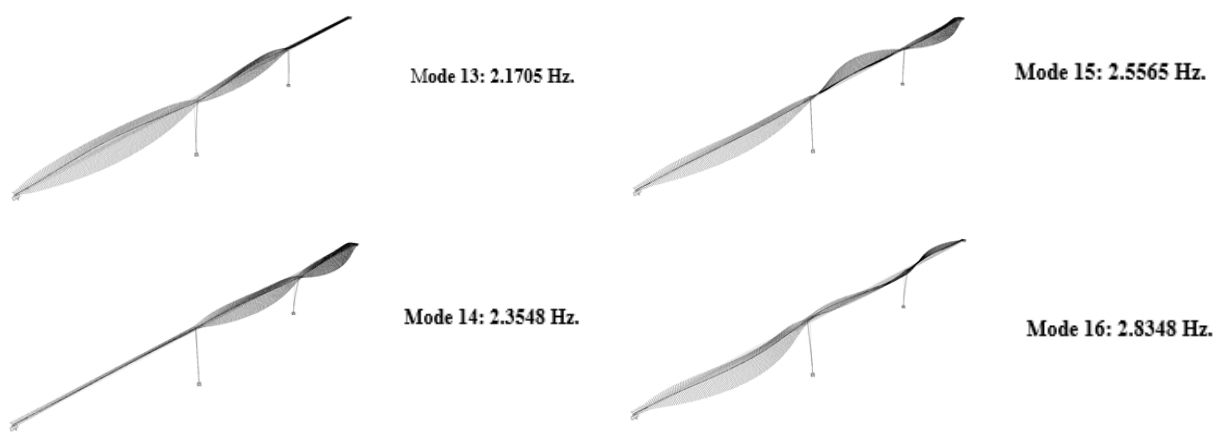

Figure 5: Geometry of torsional vibration modes.

\section{PEDESTRIAN DYNAMIC LOAD ACTING IN THREE SPANS \\ WITH VERTICAL AND LATERAL COMPONENTS}

A parametric study has been carried out considering a crowd occupying the full length of the footbridge. Two different pedestrian loads have been defined: dynamic load composed by vertical and lateral components and dynamic load composed only by lateral component. The first case represents a crowd crossing the footbridge. The second one is similar to the case when pedestrians on the bridge are still and a lateral vibration starts. This situation is quite representative of the case of the Millennium bridge a few years ago.

In both cases synchronization and non-synchronization of pedestrians were studied. In absence on actual information of damping values of the footbridge viscous damping with three value of $1 \%, 2 \%, 3 \%$ were included in the study. Forces were modeled as defined in ISO 10137. Namely

Vertical component:

$$
F_{v}(t)=p\left(1+\sum_{n=1}^{2} a_{n} \operatorname{sen} 2 \pi n f_{v} t\right)
$$

Horizontal component:

$$
F_{h}(t)=0.1 p\left(1+\sum_{n=1}^{2} a_{n} \operatorname{sen} 2 \pi n f_{v} t\right)
$$

where $p$ is a distributed load of $2.25 \mathrm{kN} / \mathrm{m}$ corresponding to three pedestrian of $750 \mathrm{~N}$ per meter or $N=648$ people in the full structure.

It can be seen that as indicated in ISO 10137 the horizontal load was $10 \%$ of the vertical component, horizontal frequency was half of the vertical one and two harmonics were considered with coefficient values of $a_{1}=0.4$ and $a_{2}=0.1$.

The range of interesting values of natural frequencies of the footbridge was between $1.2696 \mathrm{~Hz}$ (mode 1) and $4.0365 \mathrm{~Hz}$ (mode 23). Therefore a parametric study of pedestrian loads with frequencies in this interval was carried out. Maximum acceleration appeared at the nodes at span centers. Fig. 6 shows the location and the numbering of these nodes in the finite element model. Synchronized and non-synchronized behaviour of pedestrian was worked out. In the latter case a number of pedestrian of $\sqrt{N}$ or $N=648$ was assumed.

Figs 7-9 shows vertical and lateral accelerations at span centres for synchronized pedestrian vibration. It can be observed that for synchronized vibration the acceleration 


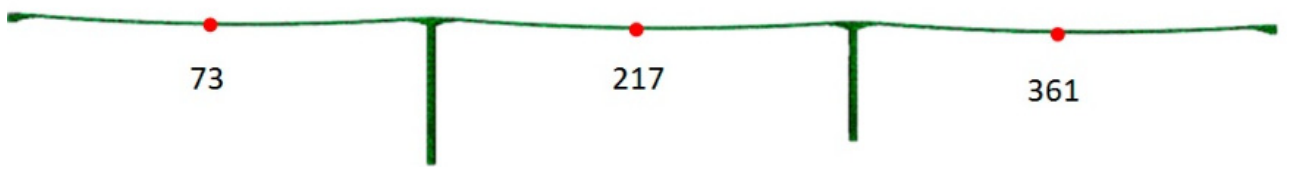

Figure 6: Numbering of nodes at span center.
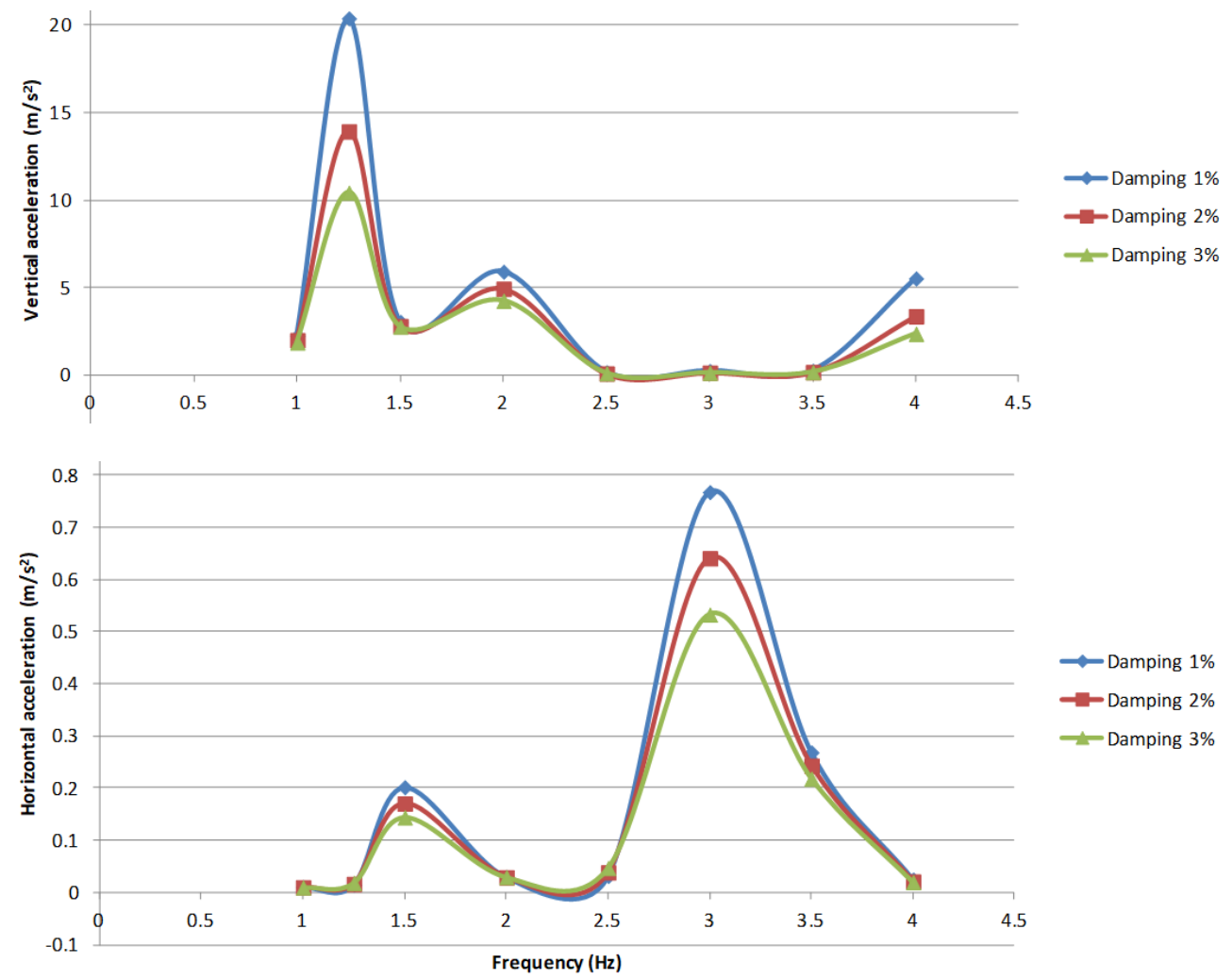

Figure 7: Vertical and horizontal accelerations at node 73 for synchronized vibration.

values are very high and of course above the allowed limit, but as mentioned before this phenomenon of totally synchronized behaviour of walking people does not happen as pedestrian react to excessive displacement by reducing their pace and also by fully stopping.

Most probable is the scenario of non-synchronized vibration and this situation is represented by assuming a number of $N$ pedestrians and using the formula of eqn (4). By doing that, the parametric study of pedestrian loads with frequencies inside the range of interest produces the results shown in Figs 10-12. As before, the maximum values appear at values of pedestrian load coincident with natural frequencies of the footbridge. Vertical accelerations reach $0.8 \mathrm{~m} / \mathrm{s}^{2}$, which is inside the allowed range of values. On the other hand, lateral accelerations are one order of magnitude below the usual limit. 
146 High Performance and Optimum Design of Structures and Materials IV
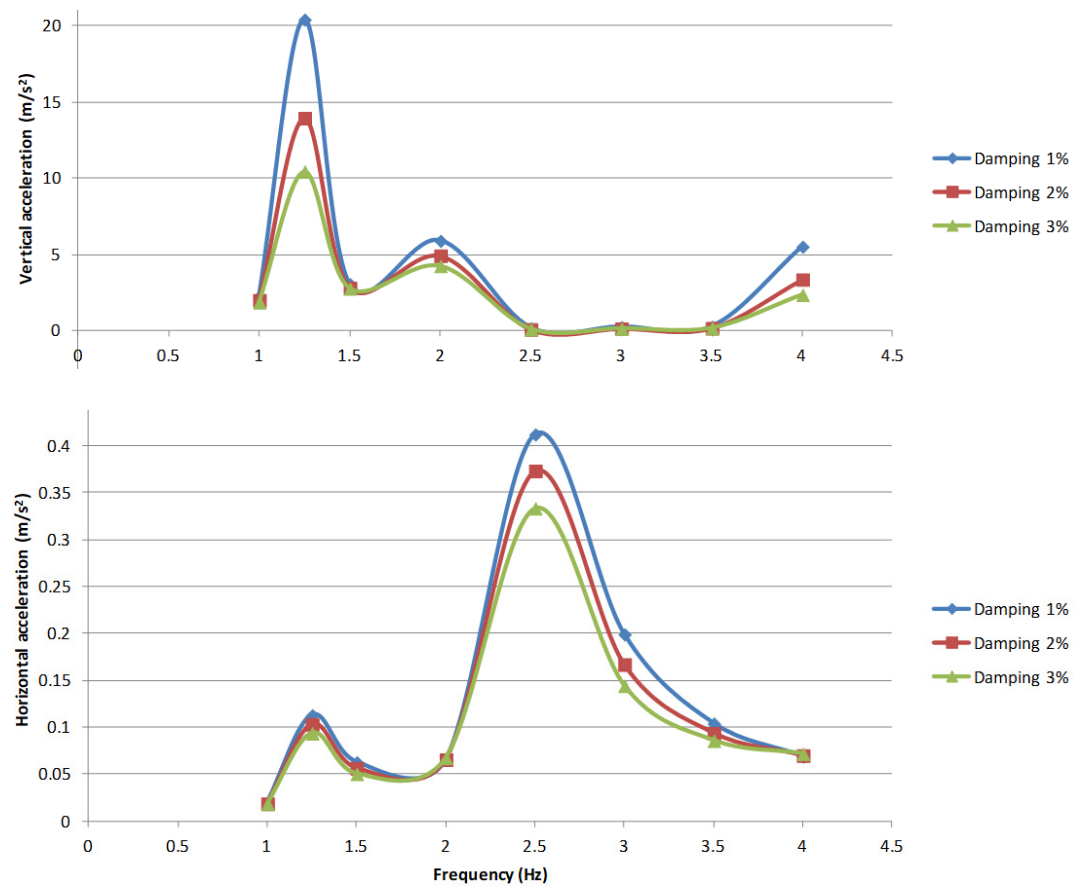

Figure 8: Vertical and horizontal accelerations at node 217 for synchronized vibration.
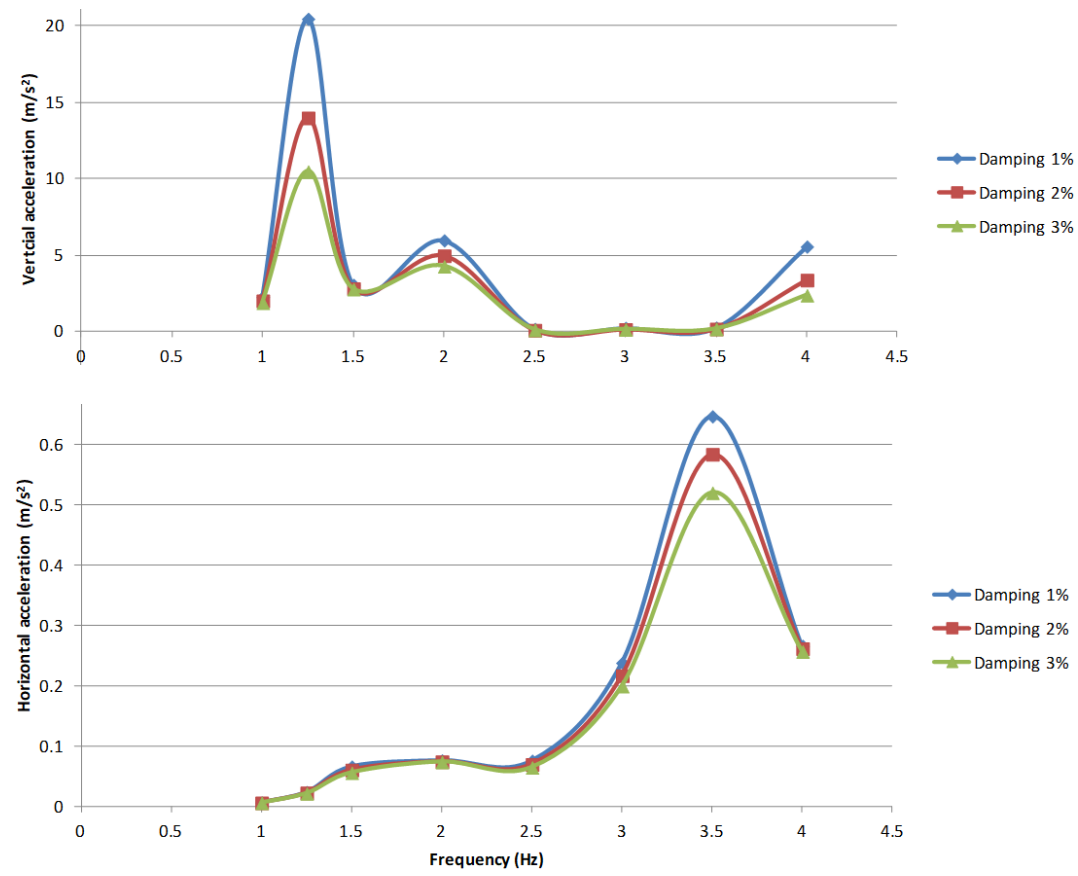

Figure 9: Vertical and horizontal accelerations at node 361 for synchronized vibration. 
High Performance and Optimum Design of Structures and Materials IV 147
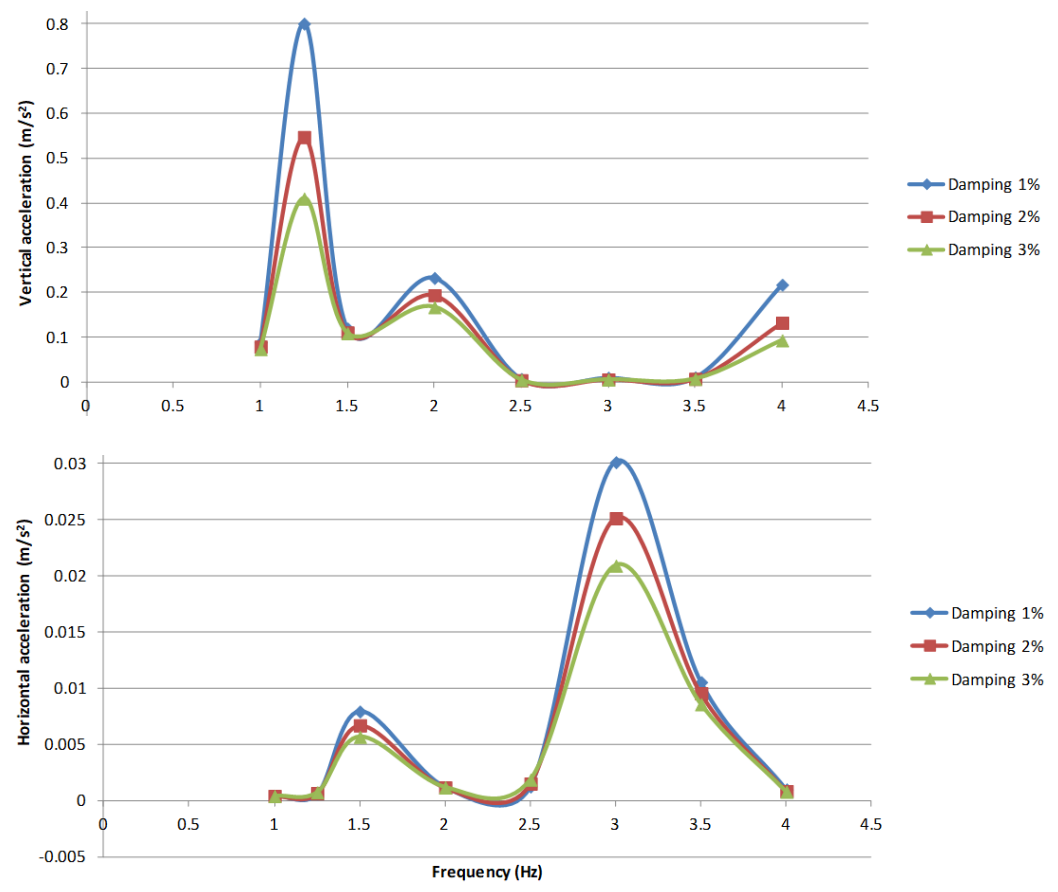

Figure 10: Vertical and horizontal accelerations at node 73 for non-synchronized vibration.
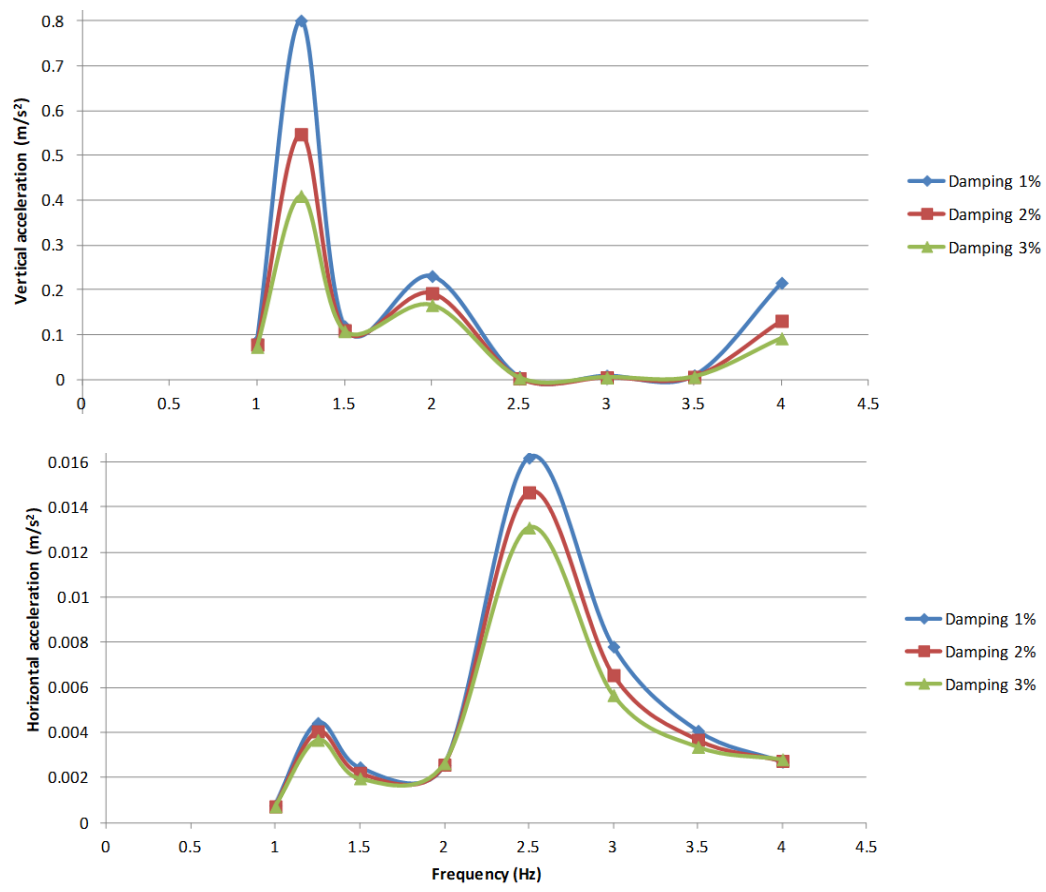

Figure 11: Vertical and horizontal accelerations at node 217 for non-synchronized vibration. 

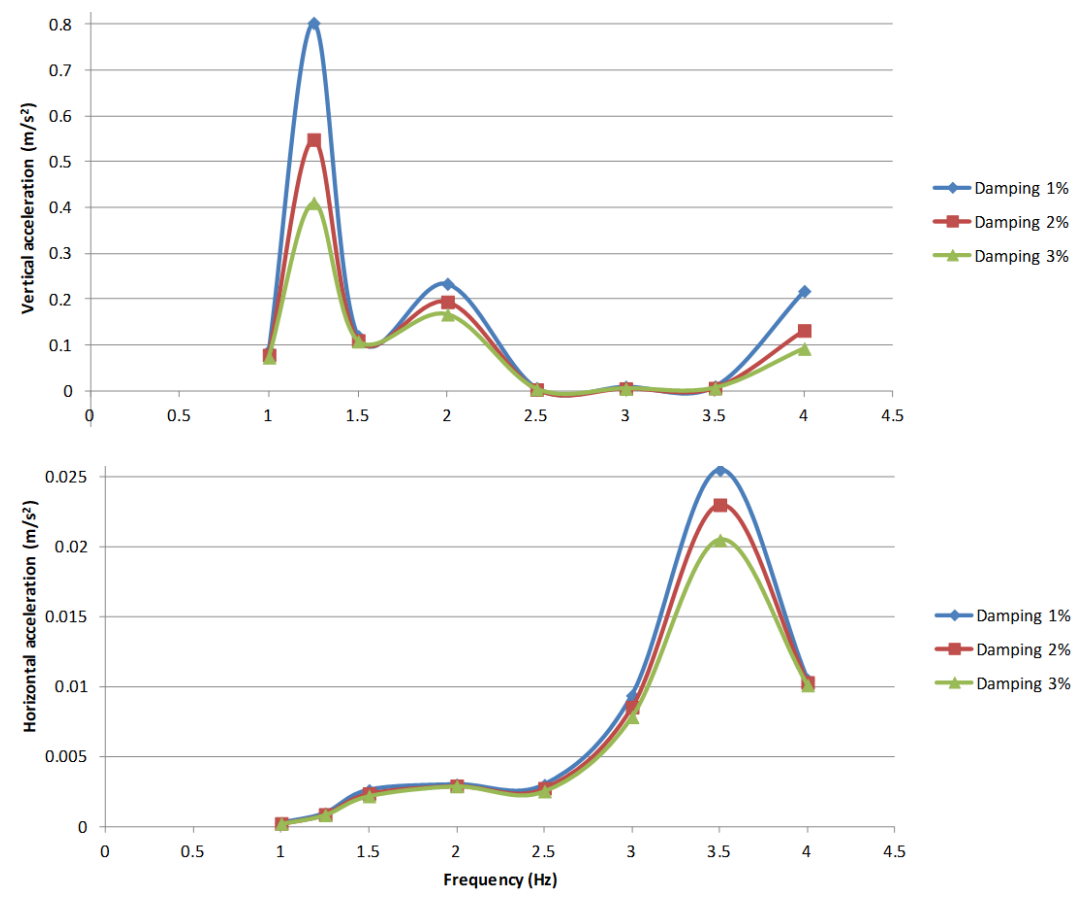

Figure 12: Vertical and horizontal accelerations at node 361 for non-synchronized vibration.

\section{PEDESTRIAN DYNAMIC LOAD CONSIDERING ONLY LATERAL COMPONENT}

As mentioned earlier this situation describes a crown standing on the footbridge when a lateral vibration initiates. The vertical component of load is considered static but a dynamic lateral component as defined previously in eqn (5) is considered.

If lateral pedestrian dynamic load acts in the three spans, using the dynamic force eqn $(5 \mathrm{~b})$ with $p=2.25 \mathrm{kN} / \mathrm{m}, a_{l h}=4$ and $a_{2 h}=0.1$, the worst scenario could be when the dynamic load has the frequency of some of the eigenfrequencies of the footbridge. In this case, the natural modes of vibration of interest are the lateral ones, namely modes 7,8 and 9 with frequencies of $1.3 \mathrm{~Hz}, 1.54 \mathrm{~Hz}$ and $1.82 \mathrm{~Hz}$. Three different situations were considered in the study:

- Include modes 7 and 8 in eqn (6).

- Include modes 8 and 9 in eqn (6).

- Include only mode 7 in eqn (6) but with value of alh $=0.5$.

The first option reproduces the vibration of the central and left spans while the second describes the vibration of central and right spans. Similarly, the third alternative corresponds to the vibration of central span alone. The numerical results obtained appear in Tables 2-7.

It can be observed that the option for choosing modes 7 and 8 produces the greatest values of acceleration at the centre of left span. Similarly when modes 8 and 9 are selected the worst situation in the right span appears. Finally the alternative using only the mode 7 with $a_{l h}=$ 0.5 produces the maximum value at the centre of the intermediate span. Values of 
Table 2: Lateral vibration considering modes 7 and 8: Synchronized vibration.

\begin{tabular}{|c|c|c|c|}
\cline { 2 - 4 } \multicolumn{1}{c|}{} & Damping value 1\% & Damping value 2\% & Damping value 3\% \\
\hline Node & Max $\ddot{\mathrm{u}}_{\mathrm{y}}\left(\mathrm{m} / \mathrm{s}^{2}\right)$ & $\operatorname{Max} \ddot{\mathrm{u}}_{\mathrm{y}}\left(\mathrm{m} / \mathrm{s}^{2}\right)$ & $\operatorname{Max} \ddot{\mathrm{u}}_{\mathrm{y}}\left(\mathrm{m} / \mathrm{s}^{2}\right)$ \\
\hline 73 & 0.820 & 0.435 & 0.309 \\
\hline 217 & 1.748 & 0.885 & 0.591 \\
\hline 361 & 0.621 & 0.333 & 0.239 \\
\hline
\end{tabular}

Table 3: Lateral vibration considering modes 8 and 9: Synchronized vibration.

\begin{tabular}{|c|c|c|c|}
\cline { 2 - 4 } \multicolumn{1}{c|}{} & Damping value 1\% & Damping value 2\% & Damping value 3\% \\
\hline Node & Max $\ddot{\mathrm{u}}_{\mathrm{y}}\left(\mathrm{m} / \mathrm{s}^{2}\right)$ & Max $\ddot{\mathrm{u}}_{\mathrm{y}}\left(\mathrm{m} / \mathrm{s}^{2}\right)$ & $\operatorname{Max} \ddot{\mathrm{u}}_{\mathrm{y}}\left(\mathrm{m} / \mathrm{s}^{2}\right)$ \\
\hline 73 & 0.394 & 0.219 & 0.168 \\
\hline 217 & 1.816 & 0.915 & 0.611 \\
\hline 361 & 1.185 & 0.599 & 0.400 \\
\hline
\end{tabular}

Table 4: Lateral vibration considering only mode 7: Synchronized vibration.

\begin{tabular}{|c|c|c|c|}
\cline { 2 - 4 } \multicolumn{1}{c|}{} & Damping value 1\% & Damping value 2\% & Damping value 3\% \\
\hline Node & Max $\ddot{\mathrm{u}}_{\mathrm{y}}\left(\mathrm{m} / \mathrm{s}^{2}\right)$ & Max $\ddot{\mathrm{u}}_{\mathrm{y}}\left(\mathrm{m} / \mathrm{s}^{2}\right)$ & $\operatorname{Max} \ddot{\mathrm{u}}_{\mathrm{y}}\left(\mathrm{m} / \mathrm{s}^{2}\right)$ \\
\hline 73 & 0.348 & 0.202 & 0.160 \\
\hline 217 & 2.109 & 1.062 & 0.707 \\
\hline 361 & 0.685 & 0.349 & 0.238 \\
\hline
\end{tabular}

Table 5: Lateral vibration considering modes 7 and 8: Non-synchronized vibration.

\begin{tabular}{|c|c|c|c|}
\cline { 2 - 4 } \multicolumn{1}{c|}{} & Damping value 1\% & Damping value 2\% & Damping value 3\% \\
\hline Node & Max $\ddot{\mathrm{u}}_{\mathrm{v}}\left(\mathrm{m} / \mathrm{s}^{2}\right)$ & $\operatorname{Max} \ddot{\mathrm{u}}_{\mathrm{v}}\left(\mathrm{m} / \mathrm{s}^{2}\right)$ & $\operatorname{Max} \ddot{\mathrm{u}}_{\mathrm{v}}\left(\mathrm{m} / \mathrm{s}^{2}\right)$ \\
\hline 73 & 0.032 & 0.017 & 0.012 \\
\hline 217 & 0.069 & 0.035 & 0.023 \\
\hline 361 & 0.024 & 0.013 & 0.009 \\
\hline
\end{tabular}

Table 6: Lateral vibration considering modes 8 and 9: Non-synchronized vibration.

\begin{tabular}{|c|c|c|c|}
\cline { 2 - 4 } \multicolumn{1}{c|}{} & Damping value 1\% & Damping value 2\% & Damping value 3\% \\
\hline Node & Max $\ddot{\mathrm{u}}_{\mathrm{y}}\left(\mathrm{m} / \mathrm{s}^{2}\right)$ & Max $\ddot{\mathrm{u}}_{\mathrm{y}}\left(\mathrm{m} / \mathrm{s}^{2}\right)$ & $\operatorname{Max} \ddot{\mathrm{u}}_{\mathrm{y}}\left(\mathrm{m} / \mathrm{s}^{2}\right)$ \\
\hline 73 & 0.015 & 0.009 & 0.007 \\
\hline 217 & 0.071 & 0.036 & 0.024 \\
\hline 361 & 0.047 & 0.024 & 0.016 \\
\hline
\end{tabular}

Table 7: Lateral vibration considering only mode 7: Non-synchronized vibration.

\begin{tabular}{|c|c|c|c|}
\cline { 2 - 4 } \multicolumn{1}{c|}{} & Damping value 1\% & Damping value 2\% & Damping value 3\% \\
\hline Node & Max $\ddot{\mathrm{u}}_{\mathrm{y}}\left(\mathrm{m} / \mathrm{s}^{2}\right)$ & Max $\ddot{\mathrm{u}}_{\mathrm{y}}\left(\mathrm{m} / \mathrm{s}^{2}\right)$ & $\operatorname{Max} \ddot{\mathrm{u}}_{\mathrm{y}}\left(\mathrm{m} / \mathrm{s}^{2}\right)$ \\
\hline 73 & 0.014 & 0.008 & 0.006 \\
\hline 217 & 0.083 & 0.042 & 0.028 \\
\hline 361 & 0.027 & 0.014 & 0.009 \\
\hline
\end{tabular}

acceleration for synchronized vibration are, again, very high but this circumstance does not occur in practice. On the other hand, the numerical results for non-synchronized vibration, with a maximum of $0.083 \mathrm{~m} / \mathrm{s}^{2}$, are far below the accepted upper limit of $0.2 \mathrm{~m} / \mathrm{s}^{2}$.

The set of lateral vibration modes of the footbridge presented in Fig. 4, namely modes $7-$ 9 , show that mostly only one span deforms. Thus, it seemed sensible to study the behaviour 
of the structure when the pedestrian dynamic load is only applied to one span. Therefore a dynamic load was defined by using eqn (5b) with $p=2.25 \mathrm{kN} / \mathrm{m}$ and $a_{h}=0.5$. Three different cases were considered:

- $\quad$ Pedestrians on the left span and $f_{h}=1.3 \mathrm{~Hz}$;

- Pedestrians on the central span and $f_{h}=1.5418 \mathrm{~Hz}$;

- Pedestrians on the right span and $f_{h}=1.8182 \mathrm{~Hz}$.

In each case the dynamic load tried to excite the natural frequency associated to the natural mode that deforms the span where the pedestrian load is defined. Both synchronized and nonsynchronized vibration were carried out and acceleration results appear in Tables 8 and 9.

Table 8: Lateral accelerations: Synchronized vibration.

\begin{tabular}{|c|c|c|c|c|}
\cline { 3 - 5 } \multicolumn{1}{c|}{} & Damping value 1\% & Damping value $2 \%$ & Damping value 3\% \\
\cline { 2 - 5 } \multicolumn{1}{c|}{} & Node & Max $\ddot{\mathrm{u}}_{\mathrm{v}}\left(\mathrm{m} / \mathrm{s}^{2}\right)$ & $\operatorname{Max} \ddot{\mathrm{u}}_{\mathrm{v}}\left(\mathrm{m} / \mathrm{s}^{2}\right)$ & Max $\ddot{\mathrm{u}}_{\mathrm{v}}\left(\mathrm{m} / \mathrm{s}^{2}\right)$ \\
\hline mode 8 & 73 & 1.961 & 0.985 & 0.657 \\
\hline mode 7 & 217 & 2.553 & 1.288 & 0.858 \\
\hline mode 9 & 361 & 2.187 & 1.094 & 0.731 \\
\hline
\end{tabular}

Table 9: Lateral accelerations: Non-synchronized vibration.

\begin{tabular}{|c|c|c|c|c|}
\cline { 3 - 5 } \multicolumn{1}{c|}{} & Damping value 1\% & Damping value $2 \%$ & Damping value 3\% \\
\cline { 2 - 5 } \multicolumn{1}{c|}{} & Node & Max $\ddot{\mathrm{u}}_{\mathrm{y}}\left(\mathrm{m} / \mathrm{s}^{2}\right)$ & Max $\ddot{\mathrm{u}}_{\mathrm{y}}\left(\mathrm{m} / \mathrm{s}^{2}\right)$ & Max $\ddot{\mathrm{u}}_{\mathrm{y}}\left(\mathrm{m} / \mathrm{s}^{2}\right)$ \\
\hline mode 8 & 73 & 0.133 & 0.067 & 0.045 \\
\hline mode 7 & 217 & 0.174 & 0.088 & 0.058 \\
\hline mode 9 & 361 & 0.149 & 0.074 & 0.050 \\
\hline
\end{tabular}

Looking at these results and those presented in Tables 2-7 it turns out that with regards to lateral vibrations is more problematic for the footbridge that the pedestrians stand only in one span that in the full length of the structure. To that extent, in the case of the synchronized vibration in Table 8, the results for node 73 must be compared to the results in Table 2, the results for node 217 with the results in Table 4 and the results for node 361 with the results in Table 3. Similarly, for the non-synchronized vibration of Table 9, comparisons should be done between the results for node 73 with the results in Table 5, for node 361 with the results in Table 7 and for node 361 with the results in Table 6 . Acceleration values of synchronized vibrations are very high, as usual, and so do the values for non-synchronized vibration but below the accepted limit.

\section{CONCLUSIONS}

A comprehensive study of an innovative three span stress ribbon footbridge has been carried out. Natural frequencies of the structure were obtained considering the structural geometry existing at the end of the construction steps with geometrical nonlinearity.

Vertical and lateral displacement are very high when fully synchronized vibration of the pedestrian load is assumed but this circumstance disagree with the behaviour of the people in real events. Regarding to the hypothesis of the non-synchronized vibration, which is more prone to occur, the worst case was identified to be when pedestrians only occupy one span of the structure but in all cases do not violate the upper values recommended in the literature. 


\section{ACKNOWLEDGEMENT}

The contribution of the Research Assistant Antia Troche in carrying out the set of dynamic analysis corresponding to the different cases of pedestrian loads is fully acknowledged and appreciated.

\section{REFERENCES}

[1] Nakamura, S.I., Lateral vibration of a pedestrian cable stayed-bridge. IABSE Journal of Structural Engineering International, 12(4), pp. 295-300, 2002.

[2] Roberts, T.M., Lateral pedestrian excitation of footbridges. J. Bridge Eng., 10(1), pp. 107-112, 2005.

[3] Dziuba, P., Grillaud, G., Flamand, O., Sanquier, S. \& Tetard, Y., La passerelle Solferino comportement dynamique. Bulletin Ouvrages Metalliques, 1(3457), 2001. (In French.)

[4] Cap, R., Gagnon, D.P. \& Zhu, T.J., Load seismic capacity evaluation and vibration analysis of the Alexandra interprovincial bridge. Developments in Short and Medium Span Bridge Engineering 2002: Papers Presented at Sixth International Conference on Short and Medium Span Bridges, Vancouver, British Columbia, Canada, 2002.

[5] Newland, D.E., Pedestrian excitation of bridges. Proc. IMechE Part C: J. Mechanical Engineering Science, 218, pp. 477-492, 2004.

[6] Newland, D.E., Vibration of London Millennium Bridge: Cause and cures. Int. J. Acoustic. Vibr, 8(1), pp. 9-14, 2003.

[7] Dallard, P., Fitzpatrick, A.J., Flint, A., Low, A., Ridsdills Smith, R.M., Willford, M. $\&$ Roche, M., London Millenium Bridge: Pedestrian-induced lateral vibrations. $J$. Bridge Eng., 6, pp. 412-417, 2001.

[8] Kala, J., Salajka, V. \& Hradel, P., Footbridge response of single pedestrian induced vibration analysis. Int. J. Eng. Applied Sci., 5(4), pp. 269-280, 2009.

[9] Huang, M.-H., Thambiratnam, D.P. \& Perera, N.J., Dynamic performance of slender inspection footbridges under eccentric walking dynamic loads. Journal of Sound and Vibration; 303, pp. 239-254, 2009.

[10] Bruno, L., Venutte, F. \& Nascé, V., Pedestrian-induced torsional vibrations of suspended footbridge: Proposal and evaluation of vibration countermeasures. Engineering Structures, 36, pp. 228-238, 2012.

[11] Zivanovic, S., Pavic, A. \& Reynolds, P., Vibration serviceability of footbridges under human-induced excitations: A literature review. J. Sound Vib., 279, pp. 1-74, 2005.

[12] ISO/CD 10137, Basis for design of structures. Serviceability of buildings and pedestrian walkways against vibration, Geneva, 2005.

[13] Blanchard, J., Davies, B.L. \& Smith, J.W., Design criteria and analysis for dynamic loading of footbridges. Proceedings of the DOE and DOT TRRL Symposium of Dynamic Behavior of Bridges, Crowthorne, UK, 19 May, pp. 90-106, 1997.

[14] Bachmann, H. \& Ammann, W., Vibrations is structures: Induced by man and machines. Structural Engineering Documents, vol. 3e, IABSE: Zürich, 1987.

[15] Young, P., Improved floor vibration prediction methodologies. Proceedings Arup's Seminar on Structural Vibration and Structure-Borne Noise: Current Developments in Assessment and Design, 4 Oct., IMechE: London, 2004.

[16] Dallard, P., Fitzpatrick, A.J., Flint, A., Low, A., Ridsdills-Smith, R.M., Willford, M. \& Roche, M., London Millenium Bridge: Pedestrian-induced lateral vibrations. $J$. Bridge Eng., 6, pp. 412-417, 2001.

[17] Nakamura, S.I., Model for lateral excitation of footbridges by synchronous walking. $J$. Struct. Eng., 130, pp. 32-37, 2004. 
152 High Performance and Optimum Design of Structures and Materials IV

[18] Fitzpatrick, A.J., Dallard, P., Le Bourva, S., Low, A., Ridsdill-Smith, R.M. \& Willford, M., Linking London: The Millenium Bridge. The Royal Academy of Engineering, Jun. 2001.

[19] Eurocode, Basis of structural design-Annex A2, EN 1990, European Committee for Standardization: Brussels, Belgium, 2002.

[20] Strasky, J., Stress Ribbon and Cable-Supported Pedestrian Bridges, 2nd ed., Institution of Civil Engineers, 2011.

[21] SAP 2000 v14, Analysis Reference Manual, Computers and Structures Inc. 